\title{
Exchange transfusion for intrahepatic cholestasis due to sickle beta thalassaemia
}

\author{
Harindra Karunatilake ${ }^{1}$, Kalyanasundaram Vithiya ${ }^{1}$, Rajaratnam Malavan ${ }^{1}$, Huseva Natalia $^{1}$ and Handun \\ Ratnayake $^{1}$
}

(Index words: intrahepatic cholestasis, sickle cell disease)

\section{Introduction}

Intrahepatic cholestasis is a rare but potentially fatal complication of sickle cell disease [1]. Sickle cell intrahepatic cholestasis (SCIC) is characterised by right upper quadrant pain, hepatomegaly and progressive hyperbilirubinaemia. To date 15 adult patients have been reported in the literature and only six survived [2]. We present a case of haemoglobin S/Beta thalassaemia with intrahepatic cholestasis successfully treated by partial exchange blood-plasma transfusion.

\section{Case report}

A 34-year old patient with haemoglobin S Beta thalassaemia presented with a three week history of jaundice and right hypochondrial pain. He did not complain of fever, anorexia or pruritus. There was no evidence of liver failure or chronic liver disease. Vital signs were normal. Sickle beta thalassaemia had been diagnosed at the age of 18 years and the patient had several episodes of haemolysis requiring blood transfusions. Investigations showed: haemoglobin $9.9 \mathrm{~g} / \mathrm{dl}$, WCC $10.8 \times 10^{9} / 1$, and platelets $407 \times 10^{9} / 1$, AST/ALT $131 / 170 \mathrm{IU} / 1$, alkaline phosphatase $294 \mathrm{U} / \mathrm{l}$, total bilirubin $215 \mu \mathrm{mol} / \mathrm{l}(102 \mu \mathrm{mol} / \mathrm{l}$ conjugated), reticulocytes $17 \%$. An ultrasound examination showed gall stones without evidence of cholecystitis or dilatation of intra- or extra-hepatic bile ducts. Serology for hepatitis B and C was negative. Over the ensuing week he developed nausea, anorexia and pruritus. Bilirubin rose to $632 \mu \mathrm{mol} / 1(513 \mu \mathrm{mol} / 1$ conjugated). Initial management included vitamin $\mathrm{K}$, blood transfusions and empirical broad spectrum antibiotics. Liver biopsy was performed. Biliary canaliculi and sinusoids distended with bile, and ballooning degeneration of hepatocytes and focal necrosis were noted. Over the next two weeks the patient became progressively more icteric and drowsy, developing asterixis and coagulopathy. He had blood stained vomiting and melaena. Investigation at this stage showed: total bilirubin $992 \mu \mathrm{mol} / \mathrm{l}(889 \mu \mathrm{mol} / 1$ conjugated), INR 3.4, haemoglobin $7.5 \mathrm{~g} / \mathrm{dl}$, WCC $35 \times 10^{9} / 1$, blood urea $37 \mathrm{mmol} / \mathrm{l}$, AST/ALT 171/81 IU/1. Partial blood-plasma exchange transfusion was carried out.
One unit of whole blood was removed and replaced with fresh frozen plasma (FFP) and one unit of cross-matched blood. This was done five times over the next 24 hours. The patient showed a dramatic improvement. Asterixis disappeared within 24 hours of exchange. By day six his total bilirubin had decreased to $359 \mu \mathrm{mol} / 1$. His biochemistry continued to improve. After four weeks his bilirubin was $137 \mu \mathrm{mol} / 1$.

\section{Discussion}

A review of liver disorders associated with sickle cell disease has identified five specific syndromes i.e., hepatic crisis, viral hepatitis, gall stones, cirrhosis and intrahepatic cholestasis [3]. SCIC has been reported in homozygous $\mathrm{HbS}$ sickle cell patients as well as in patients who are heterozygous for $\mathrm{HbS}$ and beta thalassaemia [2]. SCIC is rare but carries a grim prognosis. The aetiology remains unclear and the pathophysiology is poorly understood. SCIC is histologically characterised by intracanalicular cholestasis [4].

Only six of fifteen previously reported adult patients had survived [2]. All six had undergone exchange transfusion. However, there are three reports of SCIC with a fatal outcome despite exchange transfusion $[2,5,6]$. In one report the patient was relatively older (48 years) and had hepatitis $\mathrm{C}$ and cirrhosis [2]. In the second report the patient expired two months after discharge from hospital and he had undergone two ERCPs and a liver biopsy prior to exchange [6]. The other fatal outcome was reported in a patient with advanced hepatic fibrosis who had a complicated trans-jugular liver biopsy which required surgical intervention [5]. All of them had advanced liver disease or had undergone an intervention or both prior to exchange transfusion. This may have contributed to the bad outcome in these patients. A series from England reported a $28 \%$ incidence of death following liver biopsy in patients with sickle cell disease associated with acute hepatic disease [7]. All forms of surgery including cholecystectomy, carry a high complication rate in these patients [8].

${ }^{1}$ Base Hospital, Chilaw, Sri Lanka.

Correspondence: HK, e-mail <sanyalharindra@yahoo.com>. Received 4 March 2009 and accepted 27 June 2009. Competing interests: none declared. 
The treatment of this potentially fatal complication is not universally accepted. Early exchange transfusion seems to be the most accepted and effective form of therapy. The aim of this therapy is to reduce and maintain the haemoglobin S level at less than $30 \%$. Clinical improvement may result from the exchange transfusion of $\mathrm{RBC}$ or FFP or both [9].

\section{References}

1. Shao SH, Orringer EP. Sickle cell intrahepatic cholestasis: approach to a difficult problem. American Journal of Gastroenterology 1995; 90: 24-6.

2. Costa DB, Miksad RA, Buff MS, et al. Case of fatal sickle cell intrahepatic cholestasis despite use of exchange transfusion in an African-American patient. Journal of the American Medical Association 2006; 98: 7: 1183-7.

3. Schubert TT. Hepatobilliary system in sickle cell disease. Gastroenterology 1986; 90: 2013-21.

4. O'Callghan A, O'Brien SG, Ninkovic M, et al. Chronic intrahepatic cholestasis in sickle cell disease requiring exchange transfusion. Gut 1995; 37: 144-7.

5. Chitturi S, George J, Ranjithkumar S, et al. Exchange transfusion for severe intrahepatic cholestasis associated with sickle cell disease? Journal of Clinical Gastroenterology 2002; 35: 362-3.

6. Al-Zanaki S, Al-Saleh M. Sickle cell intrahepatic cholestasis: a rare but fatal disease. Kuwait Medical Journal 2006; 38: 326-8.

7. Zakaria N, Knisely A, Portmann B, et al. Acute sickle cell hepatopathy represents a potential contraindication for percutaneous liver biopsy. Blood 2003; 101: 101-3.

8. Vichinsky EP, Haberkorn CM, Neumayr L, et al. A comparison of conservative and aggressive transfusion regimens in the perioperative management of sickle cell disease. New England Journal of Medicine 1995; 333: 206-13.

9. Sheehy TW, Law DE, Wade BH. Exchange transfusion for sickle cell intrahepatic cholestasis. Archives of Internal Medicine 1980; 140: 1364-6. 